\title{
Pietro Garibaldi, Joaquim Oliveira Martins and Jan van Ours (eds.) (2010). Ageing, Health, and Productivity: The Economics of Increased Life Expectancy. Oxford: Oxford University Press, 288 pp. ISBN 9780199587131 (hardback)
}

\author{
REVIEWED by KatHRIN KOMP*
}

Many scholars and policy makers view longevity with concern. Longer lives, they fear, might challenge economies and welfare states. Garibaldi, Oliveira Martins and Van Ours, however, think differently. In their edited volume Ageing, Health, and Productivity, they argue that longevity can facilitate economic growth if suitable policies are implemented. Their central argument is that increased life expectancy usually goes hand in hand with increased healthy life expectancy, with the latter development opening up possibilities for healthy and active ageing. This train of thought contributes to the ongoing debates on the effects of population ageing and on policy reforms. The same train of thought also seems timely, considering that 2012 is the European Year for Active Ageing.

The book posits that longevity as such is neither good nor bad for economic growth - it is the framework of policies and market structures that determine its impact on economic growth. To develop this argument, the book proceeds in two steps. In a first step, Dormont, Oliveira Martins, Pelgrin and Suhrke discuss the interrelation between "Health expenditures, longevity, and growth". In a second step, Ilmakunnas, Van

* Kathrin Komp, Department of Sociology, Umeå University, Umeå, Sweden 
Ours, Skirbekk and Weiss describe the connection between "Age and productivity".

The section "Health expenditures, longevity and growth" underlines that longevity is often accompanied by an increasing healthy life span. This observation suggests that ageing populations can remain largely healthy populations, with largely stable health expenditures. Recent increases in health expenditure might also be attributable to technological progress, market structures and the behaviour of physicians and patients. At the same time, high health expenditures might also promote economic growth because part of this expenditure flows into research and development. Moreover, high health expenditures might lead to better health status within the population, enabling people to work until a later age and possibly also motivating them to engage in life-long learning to equip themselves for an expected longer working life. The only obstacle in the way of these economically positive developments is the current mandatory retirement age that prevents healthy people from working until a later age.

The section "Age and productivity" studies the productivity of older workers at the individual-, workgroup-, and company level. This section reports that older people maintain their level of productivity to the extent that this depends on cognitive skills, while they lose some of their productivity depending on physical strength. However, older workers themselves feel that their working capacity declines only slightly with age. Moreover, compared to younger workers, older workers are absent less often, but they have longer periods of absence. Finally, the age composition of workers within working groups influences productivity, in that agediverse working groups are less productive than age-homogeneous ones. At the company level, however, no such effects exist.

The two main sections of the book have very different writing styles and analytical approaches. The section on health is rich in new and exciting ideas, but its main arguments are based on a thin empirical basis. The ideas sometimes follow each other in quick succession, which does not always give them all the room and attention they deserve. In this sense, I agree with Axel Börsch-Supan that many of the ideas in this section deserve fuller explanations, maybe even in separate papers (p. 116). The section on productivity, in contrast, is focused and many of its statements are grounded in analyses of datasets from Germany and Finland. Here, 
a stronger theoretical discussion would have been preferable. However, an excellent presentation of the conclusions and policy implications of the analyses makes up for this shortcoming.

I should also compliment the editors of the book for coming up with a structure, where each of the two sections ends with a short chapter on policy implications as well as two short essays by external experts who discuss the sections and findings. This structure makes the relevance of the topic easier to grasp and it gives the reader the feeling of participating in a lively, ongoing scholarly discussion.

Besides its merits, however, the book also has some limitations. The main limitation becomes obvious in the second section of the book, which promises a discussion on productivity, but it in fact only deals with paid work. Gerontologists might raise their eyebrows about this narrow understanding of productivity, considering that feminist gerontology and the concept of productive ageing advocate also recognising activities such as informal caregiving and volunteering as productive. The authors probably did not pick up on those debates because they are economists, not gerontologists. This disciplinary perspective accounts for both the weakness and the strength of this book. The weakness is that many concepts central to social gerontology, such as productive ageing, gender differences and social inequalities, are not reflected in the book. The narrative would have been stronger had those concepts been considered. The strength is that this book applies a non-gerontological perspective to a gerontological topic, thereby enriching discussions on population ageing and serving as an eye-opener in many respects.

Overall, I very much enjoyed reading this book. It provides gerontologists with a new perspective on possible effects of ageing populations, which can enhance our discussions and serve as a starting point for new studies. Especially, the section on health and productivity can give us such food for thought. The book is probably most suitable for gerontologists familiar with discussions on the effects of population ageing. When it is presented together with introductory gerontological texts, this book can also be useful in teaching situations, where it might start critical and differentiated discussions. Given a proper framing, this book might, therefore, appeal to emerging as well as experienced gerontological scholars. 